\title{
Effectiveness of interventions designed to reduce the use of imaging for low-back pain: a systematic review
}

\author{
Hazel J. Jenkins MChir, Mark J. Hancock PhD, Simon D. French PhD, Chris G. Maher PhD, \\ Roger M. Engel PhD, John S. Magnussen PhD
}

\begin{abstract}
Background: Rates of imaging for low-back pain are high and are associated with increased health care costs and radiation exposure as well as potentially poorer patient outcomes. We conducted a systematic review to investigate the effectiveness of interventions aimed at reducing the use of imaging for low-back pain.
\end{abstract}

Methods: We searched MEDLINE, Embase, CINAHL and the Cochrane Central Register of Controlled Trials from the earliest records to June 23, 2014. We included randomized controlled trials, controlled clinical trials and interrupted time series studies that assessed interventions designed to reduce the use of imaging in any clinical setting, including primary, emergency and specialist care. Two independent reviewers extracted data and assessed risk of bias. We used raw data on imaging rates to calculate summary statistics. Study heterogeneity prevented meta-analysis.

Results: A total of 8500 records were identified through the literature search. Of the 54 potentially eligible studies reviewed in full, 7 were included in our review. Clinical decision support involving a modified referral form in a hospital setting reduced imaging by $36.8 \%$ (95\% confidence interval [Cl] $33.2 \%$ to $40.5 \%$ ). Targeted reminders to primary care physicians of appropriate indications for imaging reduced referrals for imaging by $22.5 \%(95 \% \mathrm{Cl}$ $8.4 \%$ to $36.8 \%$ ). Interventions that used practitioner audits and feedback, practitioner education or guideline dissemination did not significantly reduce imaging rates. Lack of power within some of the included studies resulted in lack of statistical significance despite potentially clinically important effects.

Interpretation: Clinical decision support in a hospital setting and targeted reminders to primary care doctors were effective interventions in reducing the use of imaging for low-back pain. These are potentially low-cost interventions that would substantially decrease medical expenditures associated with the management of low-back pain.

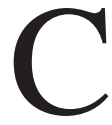
urrent evidence-based clinical practice guidelines recommend against the routine use of imaging in patients presenting with low-back pain. ${ }^{1-3}$ Despite this, imaging rates remain high, ${ }^{4,5}$ which indicates poor concordance with these guidelines. ${ }^{6,7}$

Unnecessary imaging for low-back pain has been associated with poorer patient outcomes, increased radiation exposure and higher health care costs. ${ }^{8}$ No short- or long-term clinical benefits have been shown with routine imaging of the low back, and the diagnostic value of incidental imaging findings remains uncertain. ${ }^{9-12}$ A 2008 systematic review found that imaging accounted for $7 \%$ of direct costs associated with low-back pain, which in 1998 translated to more than US $\$ 6$ billion in the United States and $£ 114$ million in the United Kingdom. ${ }^{13}$ Current costs are likely to be substantially higher, with an esti- mated $65 \%$ increase in spine-related expenditures between 1997 and 2005. ${ }^{14}$

Various interventions have been tried for reducing imaging rates among people with lowback pain. These include strategies targeted at the practitioner such as guideline dissemination, ${ }^{15-17}$ education workshops, ${ }^{18,19}$ audit and feedback of imaging use, ${ }^{7,20,21}$ ongoing reminders ${ }^{7}$ and clinical decision support. ${ }^{22-24}$ It is unclear which, if any, of these strategies are effective..$^{25}$ We conducted a systematic review to investigate the effectiveness of interventions designed to reduce imaging rates for the management of low-back pain.

\section{Methods}

We designed the review protocol based on guidelines produced by the Cochrane Effective Practice and Organisation of Care (EPOC) Re-
Competing interests: Mark Hancock has received research grants from GlaxoSmithKline and Pfizer. Chris Maher has received research grants from GlaxoSmithKline, Pfizer, WorkCover of New South Wales, Motor Accidents Authority of New South Wales, Motor Accidents Insurance Commission of Queensland, New South Wales Health, WorkCover of South Australia, WorkSafe Victoria and the Transport Accident Commission of Victoria, Australia; he is involved in the PEDro project (Physiotherapy Evidence Database), which is supported by several organizations (www.pedro .org.au/english/supporters/); and he received a fee to review education material from GlaxoSmithKline. No other competing interests were declared.

This article has been peer reviewed.

Correspondence to:

Hazel Jenkins, hazel.jenkins @mq.edu.au

Accepted: Jan. 28, 2015 Published: Mar. 2, 2015

CMAJ 2015. DOI:10.1503 /cmaj.141183 
view Group ${ }^{26}$ and the PRISMA statement. ${ }^{27}$ The review protocol was registered with PROSPERO (www.crd.york.ac.uk/PROSPERO; registration no. CRD42013005842).

\section{Data sources and inclusion criteria}

We searched MEDLINE, Embase, CINAHL and the Cochrane Central Register of Controlled Trials from the earliest records to June 23, 2014. The search terms we used related to low-back pain, diagnostic imaging, interventions and study design, appropriately modified for each database (details of the search strategies appear in Appendix 1, available at www.cmaj.ca/lookup/suppl /doi:10.1503/cmaj.141183/-/DC1). We also conducted forward and backward tracking of citations in the studies identified by the search that were reviewed in full and in any relevant review articles.

Studies were eligible if they assessed patients with low-back pain using an intervention designed to reduce the use of imaging in any clinical setting, including primary, emergency and specialist care. Included study designs were randomized controlled trials (RCTs), controlled clinical trials and interrupted time series studies. We included interrupted time series studies only if they had at least 3 individual data-collection points before and after the intervention ${ }^{26}$ to allow calculation of linear trend lines. Controlled before-after studies were not considered to provide sufficiently robust evidence owing to the possibility of inherent differences between study groups. ${ }^{28}$ The comparator could include any other intervention, usual care or no intervention. The outcome had to be measured as either rates of imaging or counts of the number of images, and the imaging modality could be plain radiography, computed tomography $(\mathrm{CT})$ or magnetic resonance imaging (MRI). We excluded studies that reported imaging of the "back" or "spine" because they were not considered sufficiently specific. We included only studies written in English.

\section{Study selection}

One of us (H.J.J.) reviewed the titles of the retrieved articles and excluded clearly irrelevant ones. Two of us (H.J.J. and M.J.H.) independently reviewed the titles and abstracts of the remaining articles for inclusion. Finally, we all worked in pairs to independently assess the full-text versions of potentially eligible articles for final inclusion in the review. Disagreements that could not be resolved by discussion between a pair of reviewers were arbitrated by a third reviewer.

Data extraction and quality assessment Two of us (H.J.J., M.J.H. or S.D.F.) independently extracted the data from each included study and performed a risk-of-bias assessment. The form used to collect data was modified from the EPOC data collection checklist ${ }^{26}$ and piloted before use on an included study. Discrepancies between collected data were discussed, and disagreements were resolved through consultation with a third reviewer. The risk-of-bias assessment was performed as outlined in the Cochrane Handbook for Systematic Reviews of Interventions $^{29}$ with validated modifications based on the EPOC guidelines. ${ }^{26}$ Risk of bias for RCTs and interrupted time series studies was assessed separately with the use of different criteria. Assessment of the reliability of the primary outcome measure was affected by the patient population defined in the study (patients with low-back pain or patients presenting with any complaint) and whether the total number of patients assessed was reported.

\section{Data synthesis and analysis}

The primary outcome was imaging for low-back pain. In studies that assessed different types of imaging modalities separately, outcomes were reported according to imaging type (e.g., radiography, CT or MRI). Secondary outcomes included health outcomes and patient satisfaction with care. We collected data on health outcomes and patient satisfaction only from studies that also reported on use of imaging.

We assessed the homogeneity of the studies to determine if pooling of data and meta-analysis were appropriate. Homogeneity of study design, type of intervention, patient characteristics (presenting condition), clinical setting (primary or secondary care) and outcome measure were determined necessary for pooling data across studies.

For RCTs, raw primary outcome data were extracted where available and summary statistics were calculated. Risk ratios and $95 \%$ confidence intervals (CIs) were calculated for dichotomous outcomes, and the percentage mean difference in the change scores ${ }^{30}$ with $95 \%$ CIs were calculated for continuous outcomes. Variation inflation factors could not be calculated from the available raw data, and these studies could not be adjusted for clustering. Therefore, originally reported effect sizes (adjusted for clustering) and $95 \%$ CIs were also presented to capture this variance.

For interrupted time series studies, outcome data were extracted and summary statistics were calculated. Before-after analysis was performed by means of calculating the mean difference and 95\% CIs between mean values before and after the intervention. Time series regression analysis was performed, as described by Ramsay and colleagues, ${ }^{31}$ to reduce bias associated with before- 
after analysis. Two measures of effect size were calculated with 95\% CIs: the change in slope of the regression lines and the change in estimated outcome measure at the first time point after the intervention.

Secondary outcome data, where available, were calculated in a similar fashion to primary outcome data.

\section{Results}

\section{Study characteristics}

We identified 8488 records through the electronic database search. A further 12 records were found through forward and backward tracking of citations in the 42 studies identified by the search that were reviewed in full. Of the 54 studies reviewed in full, 47 were excluded (Figure 1). Common reasons for exclusion included lack of a specific intervention designed to reduce imaging rates, lack of data on imaging rates and study designs that did not meet the inclusion criteria. One study ${ }^{31}$ was excluded because it reanalyzed the same data as another included study. ${ }^{7}$

The characteristics of the included studies are depicted in Table 1 . The studies comprised 5 cluster RCTs ${ }^{7,18-21}$ and 2 interrupted time series studies. ${ }^{17,24}$ One trial was performed in a hospital setting $^{24}$ with the remainder in primary care. The interventions investigated in the studies were divided into 4 categories: clinical decision support and targeted reminders, ${ }^{7,24}$ audit and feedback, ${ }^{7,20,21}$ practitioner education ${ }^{18,19}$ and postal guideline dissemination. ${ }^{17}$ The control groups either had no intervention ${ }^{19-21}$ or received dissemination of clinical guidelines. ${ }^{7,18}$ Outcome measures varied between studies. Two studies ${ }^{19,20}$ enrolled patients presenting to primary care with low-back pain and reported whether they received imaging (yes or no). Two other studies ${ }^{7,18}$ enrolled primary care clinics into the study and reported imaging expressed as rates (low-back imaging per 1000 patients seen); in these 2 studies, imaging rates were not confined to patients presenting with low-back pain. Three studies ${ }^{17,21,24}$ reported imaging counts that were not confined to patients presenting with low-back pain; the total number of patients presenting for care was not reported.

\section{Risk-of-bias assessment}

Findings from the risk-of-bias assessment are summarized in Table 2. All of the RCTs reported using adequate randomization and allocation procedures and objective outcome measures. However, they were unable to blind the practitioners involved in the study.

Across all studies, we considered the primary outcome measure to be reliable in the 2 studies reporting on imaging among low-back pain patients only. ${ }^{19,20}$ The studies reporting on rates per 1000 patients presenting with any complaint ${ }^{7,18}$ were considered to have outcome measures of uncertain reliability. Those reporting counts of imaging ${ }^{17,21,24}$ were considered to have unreliable outcome measures.

\section{Effectiveness of interventions}

The results of the included studies are summarized in Table 3. No 2 studies exhibited sufficient similarity in intervention type, study design and outcome measure to allow meta-analysis to be performed.

\section{Clinical decision support and targeted reminders}

These types of interventions appeared to produce the largest reductions in imaging. ${ }^{7,24}$ The interrupted time series study by Baker and colleagues ${ }^{24}$ investigated a clinical decision support consisting of a modified referral form that allowed only 3 guideline-appropriate indications

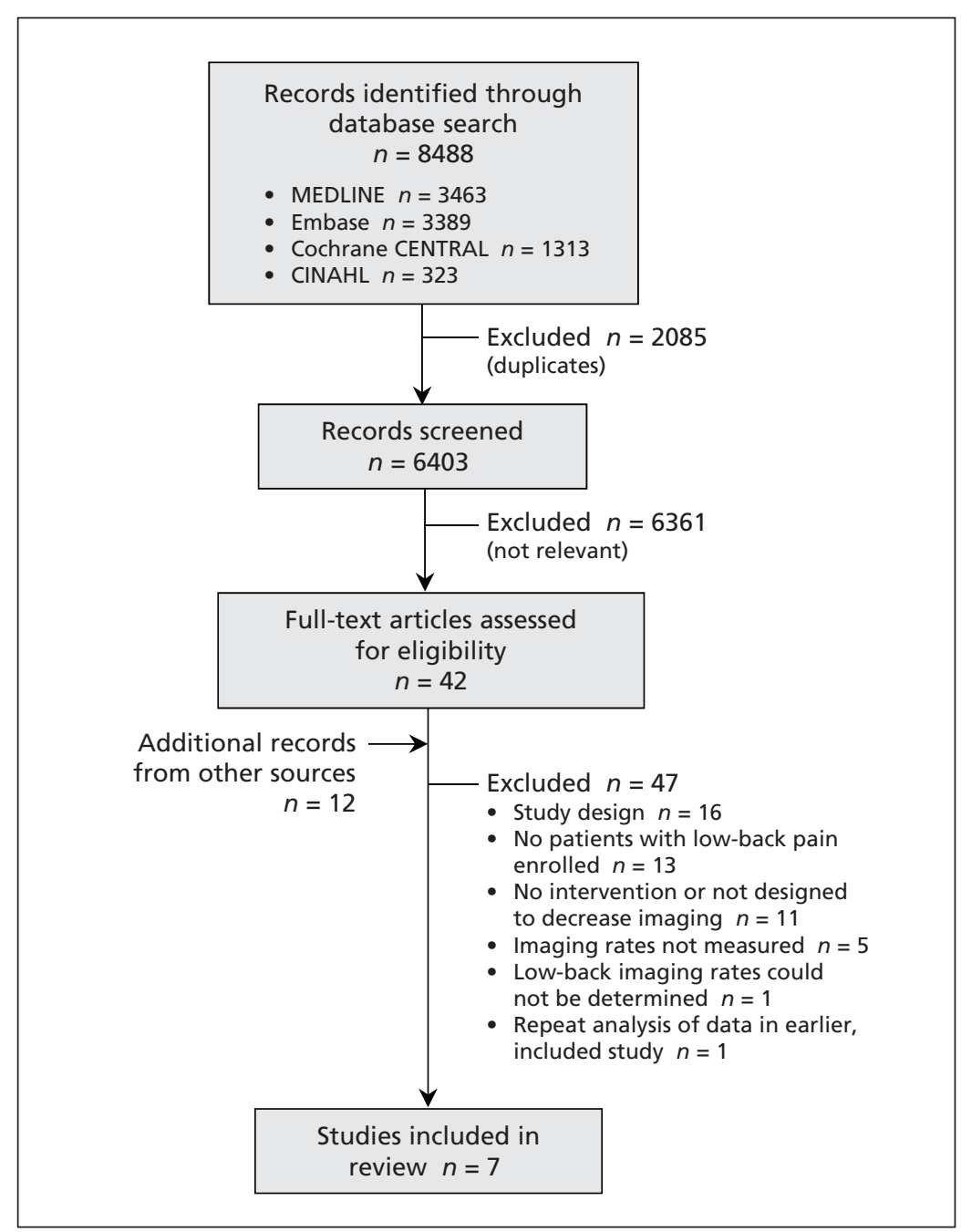

Figure 1: Selection of studies for the systematic review. 
for imaging. ${ }^{24}$ Although time series regression analysis was not performed in the original study, we were able to conduct it with the data reported. We found a statistically significant decrease in the absolute change in referrals in the month after implementation of the new forms (absolute change $-44.3,95 \% \mathrm{CI}-48.7$ to -39.9 ), equivalent to a decrease in imaging of $36.8 \%$ (95\% CI $33.2 \%$ to $40.5 \%)$. The associated change in slope of the regression lines exhibited wide $95 \%$ CIs, which made it unclear whether the initial decrease in imaging referrals would be maintained over time (change in slope 1.99, $95 \%$ CI -2.1 to 6.1 ). The total number of presenting patients was not reported, which limited the strength of these findings.

An intervention using targeted reminders was investigated by Eccles and colleagues. ${ }^{7}$ A short educational message promoting correct imaging practices was attached to all reports of lumbar spine imaging sent to practitioners during the intervention period. ${ }^{7}$ After adjustment for clustering, the authors found a statistically significant absolute change in imaging of -1.5 radiographs per 1000 patients $(95 \%$ CI -2.5 to -0.6$)$ from
6.8 radiographs per 1000 patients in the control group; this change was equivalent to a reduction in imaging of $22.5 \%$ (95\% CI $8.4 \%$ to $36.8 \%$ ).

\section{Audit and feedback}

Audit and feedback interventions were associated with variable results. Audit and feedback involved collection of previous data on imaging referral rates and feedback of that information to practitioners in the intervention group. Kerry and colleagues $^{21}$ provided feedback on individual practice referral rates at the start of the intervention period only. They found a $20 \%$ (95\% CI 3\% to $37 \%$ ) reduction in imaging after the intervention compared with the control group, which received no feedback. However, the total number of presenting patients was not reported, which limited the strength of the finding.

Eccles and colleagues ${ }^{7}$ provided feedback on routine referral rate data at the start of the intervention period and 6 months later. After adjusting for clustering, they found no significant change in imaging rates in the intervention group compared with the control group, which received guideline dissemination.

Table 1: Characteristics of studies included in the systematic review

\begin{tabular}{|c|c|c|c|c|c|}
\hline Study & Intervention & Control & Clinical setting & Patients & Outcome measure \\
\hline \multicolumn{6}{|l|}{ Cluster RCT } \\
\hline Eccles et al. ${ }^{7}$ & $\begin{array}{l}\text { 1. Audit and feedback } \\
\text { 2. Reminders } \\
\text { 3. Both }\end{array}$ & $\begin{array}{l}\text { Guideline } \\
\text { dissemination }\end{array}$ & $\begin{array}{l}243 \text { general } \\
\text { practices }\end{array}$ & $\begin{array}{l}\text { All patients with any } \\
\text { clinical presentation } \\
\text { (no. not reported) }\end{array}$ & $\begin{array}{l}\text { Imaging rate per } \\
1000 \text { patients }\end{array}$ \\
\hline French et al. ${ }^{18}$ & Practitioner education* & $\begin{array}{l}\text { Guideline } \\
\text { dissemination }\end{array}$ & $\begin{array}{l}92 \text { general } \\
\text { practices }\end{array}$ & $\begin{array}{l}152942 \text { (77 } 716 \\
\text { intervention, } 75226 \\
\text { control) with any } \\
\text { clinical presentation }\end{array}$ & $\begin{array}{l}\text { Imaging rate per } \\
1000 \text { patients }\end{array}$ \\
\hline Dey et al. ${ }^{19}$ & $\begin{array}{l}\text { Practitioner education* } \\
\text { with guidelines on } \\
\text { secondary care referral }\end{array}$ & No intervention & $\begin{array}{l}23 \text { general } \\
\text { practices }\end{array}$ & $\begin{array}{l}2187 \text { (1 } 049 \text { intervention, } \\
1138 \text { control) with } \\
\text { acute low-back pain }\end{array}$ & $\begin{array}{l}\text { Imaging rate }(\%) \\
\text { among patients } \\
\text { with low-back pain }\end{array}$ \\
\hline $\begin{array}{l}\text { Schectman } \\
\text { et al. }{ }^{20}\end{array}$ & $\begin{array}{l}\text { 1. Practitioner education } \\
\text { with audit and } \\
\text { feedback } \\
\text { 2. Patient education } \\
\text { 3. Both }\end{array}$ & No intervention & $\begin{array}{l}14 \text { general } \\
\text { practices }\end{array}$ & $\begin{array}{l}4066 \text { (2 } 020 \text { baseline } \\
\text { year, } 2046 \text { study year) } \\
\text { with acute low-back } \\
\text { pain }\end{array}$ & $\begin{array}{l}\text { Imaging rate }(\%) \\
\text { among patients } \\
\text { with low-back pain }\end{array}$ \\
\hline Kerry et al. ${ }^{21}$ & $\begin{array}{l}\text { Guideline dissemination } \\
\text { with audit and feedback }\end{array}$ & No intervention & $\begin{array}{l}69 \text { general } \\
\text { practices }\end{array}$ & $\begin{array}{l}\text { All patients with any } \\
\text { clinical presentation } \\
\text { (no. not reported) }\end{array}$ & $\begin{array}{l}\text { No. of imaging } \\
\text { referrals }\end{array}$ \\
\hline \multicolumn{6}{|c|}{ Interrupted time series } \\
\hline Matowe et al. ${ }^{17}$ & Guideline dissemination & NA & $\begin{array}{l}87 \text { general } \\
\text { practices }\end{array}$ & $\begin{array}{l}\text { All patients with any } \\
\text { clinical presentation } \\
\text { (no. not reported) }\end{array}$ & $\begin{array}{l}\text { No. of imaging } \\
\text { referrals }\end{array}$ \\
\hline Baker et al. ${ }^{24}$ & Clinical decision support† & NA & Hospital & $\begin{array}{l}\text { All patients with any } \\
\text { clinical presentation } \\
\text { (no. not reported) }\end{array}$ & $\begin{array}{l}\text { No. of imaging } \\
\text { referrals }\end{array}$ \\
\hline
\end{tabular}


In the study by Schectman and colleagues, ${ }^{20}$ practitioners in the intervention group attended an education session and received individual feedback about their clinical performance at the start of the intervention period and 6 months later; those in the control group received no intervention. The analysis did not adjust for clustering. A statistically significant decrease in imaging was not shown compared with the control group.

\section{Practitioner education}

No evidence of effectiveness was shown for interventions that involved face-to-face education sessions between primary care doctors and an educational team. Dey and colleagues, ${ }^{19}$ after adjusting for between-cluster variance, showed a $1.4 \%$ (95\% CI $-4.1 \%$ to $6.8 \%$ ) increase in imaging compared with the control group, which received no intervention.

French and colleauges ${ }^{18}$ compared practitioner education with guideline dissemination. After adjusting for clustering, they found a $17 \%$ decrease in radiographs (incident rate ratio [IRR] $0.8,95 \%$ CI 0.6 to 1.1 ) and an $8 \%$ decrease in CT scans (IRR 0.9, 95\% CI 0.7 to 1.3 ). However, the associated $95 \%$ CIs failed to show statistical significance.

\section{Guideline dissemination}

No evidence of effectiveness was shown for postal dissemination of guidelines as an intervention. Guideline dissemination was assessed as the primary intervention only by Matowe and colleagues ${ }^{17}$ and involved the postal distribution of current clinical guidelines to the intervention group. Time series regression analysis failed to show statistically significant findings in either the absolute change in referrals in the first month after the intervention or in the sustained effect of the intervention over time.

\section{Effect on secondary outcomes}

The studies by Dey and colleagues ${ }^{19}$ and Schectman and colleagues ${ }^{20}$ were the only ones that reported on health outcomes, including prescribed sickness certificates, prescribed medication and referral to secondary care. The results are summarized in Appendix 2 (available at www.cmaj.ca /lookup/suppl/doi:10.1503/cmaj.141183/-/DC1). The only statistically significant effect was shown with the use of practitioner education as an intervention. ${ }^{19}$ After adjustment for cluster variance, Dey and colleagues found a $12.2 \%$ (95\% CI $2.8 \%$ to $21.6 \%$ ) increase in the number of patients in the intervention group being referred to physiotherapy or to educational programs at the back clinic. The increase in these referrals was considered to be a positive effect of the intervention.

\section{Interpretation}

Our systematic review showed that the use of imaging for low-back pain was significantly reduced with interventions involving clinical deci-

Table 2: Risk-of-bias assessment of studies included in the systematic review

\begin{tabular}{|c|c|c|c|c|c|c|c|c|c|c|c|c|}
\hline Cluster RCT & 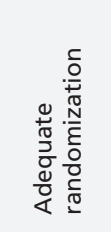 & 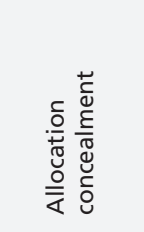 & 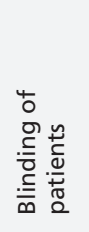 & 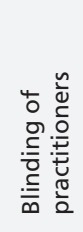 & 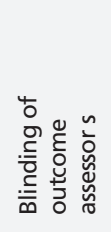 & 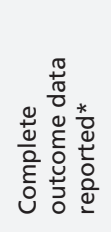 & 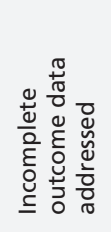 & 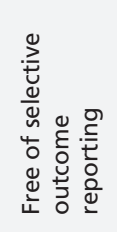 & 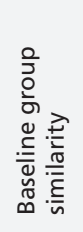 & 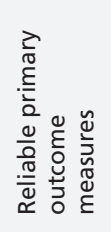 & 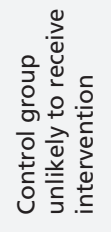 & 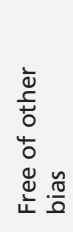 \\
\hline Eccles et al. ${ }^{7}$ & $Y$ & Y & NA & $\mathrm{N}$ & Y & Y & NA & Y & $\mathrm{N}$ & U & $Y$ & $Y$ \\
\hline French et al. ${ }^{18}$ & Y & Y & NA & $\mathrm{N}$ & Y & $\mathrm{N}$ & Y & Y & $\mathrm{N}$ & U & Y & $Y$ \\
\hline Kerry et al..$^{21}$ & Y & Y & NA & $\mathrm{N}$ & Y & U & u & Y & U & $\mathrm{N}$ & $Y$ & $Y$ \\
\hline Schectman et al..$^{20}$ & Y & $Y$ & NA & $\mathrm{N}$ & $Y$ & $Y$ & NA & U & $\mathrm{N}$ & Y & Y & $\mathrm{N}$ \\
\hline $\begin{array}{l}\text { Interrupted } \\
\text { time series }\end{array}$ & 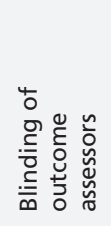 & 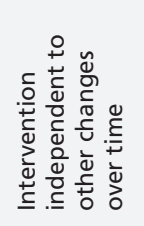 & 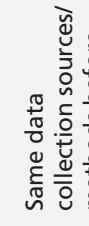 & 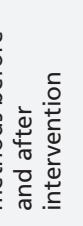 & 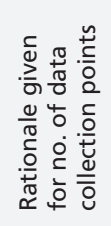 & 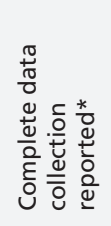 & 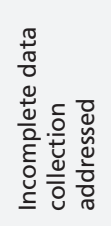 & 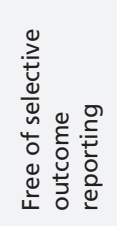 & 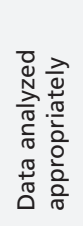 & 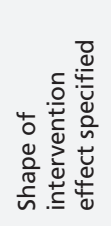 & 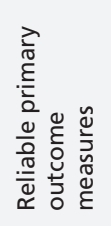 & 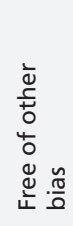 \\
\hline Matowe et al. ${ }^{17}$ & $Y$ & u & 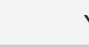 & & $\mathrm{N}$ & Y & NA & Y & Y & Y & $\mathrm{N}$ & $\mathrm{N}$ \\
\hline Baker et al. ${ }^{24}$ & $Y$ & u & 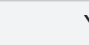 & & $\mathrm{N}$ & $u$ & u & $u$ & $\mathrm{~N}$ & $\mathrm{~N}$ & $\mathrm{~N}$ & $\mathrm{Y}$ \\
\hline
\end{tabular}


sion support $(36.8 \%$ reduction in a hospital setting) and targeted reminders $(22.5 \%$ reduction in a primary care setting). However, because of the small number of studies evaluating these inter- ventions, the results should be interpreted with caution. Practitioner audit and feedback showed a statistically significant reduction of $20 \%$ in imaging in one study; however, a similar interven-

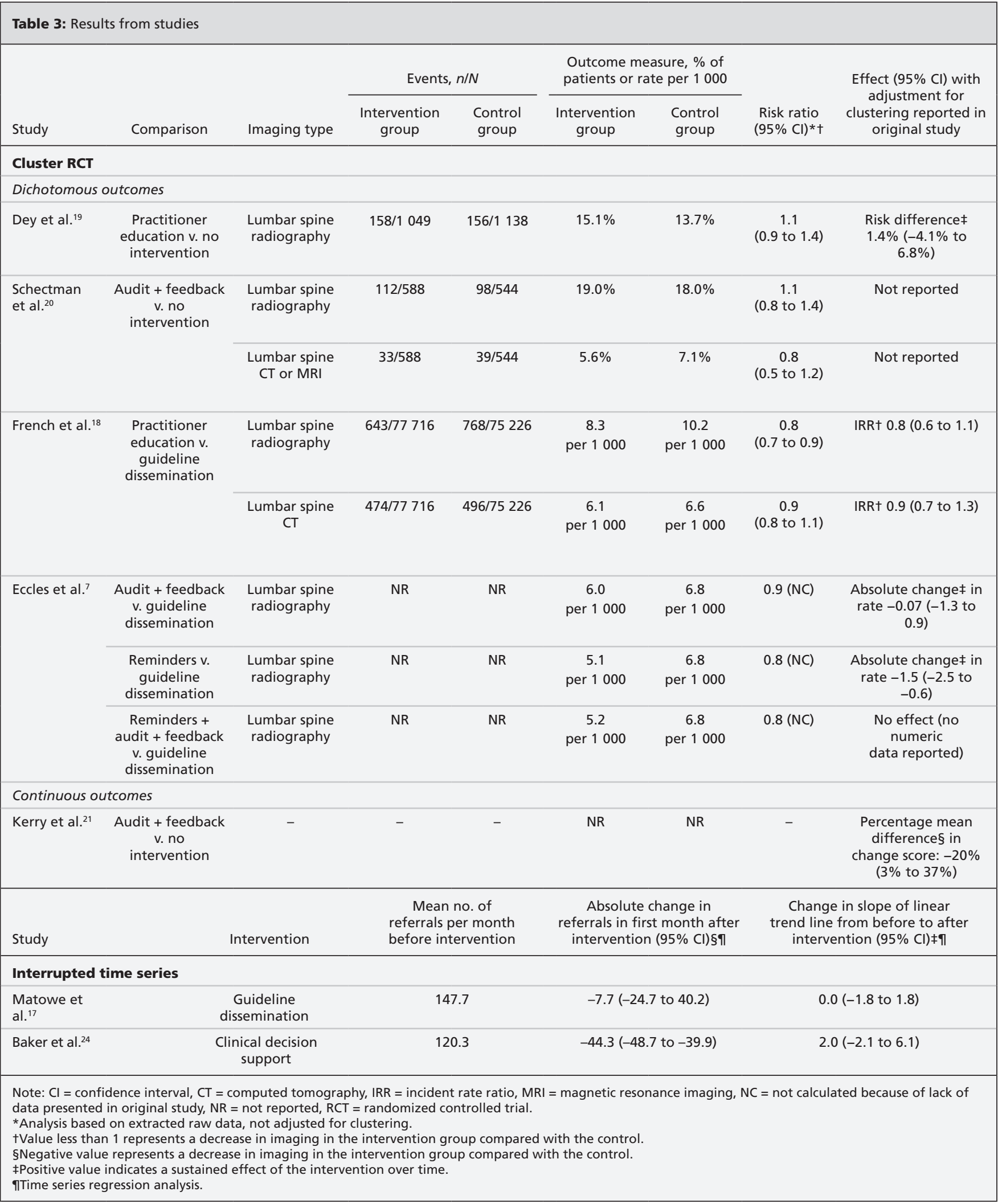


tion in 2 other studies had no statistically significant effect. Practitioner education and guideline dissemination did not seem to be effective strategies for reducing imaging for low-back pain.

In a previous systematic review, French and colleagues $^{25}$ assessed the effect of interventions aimed at improving appropriate imaging of the lumbar spine for any musculoskeletal condition. The broad nature of the research question did not allow for the targeted focus on low-back pain presented in our review. Furthermore, the search strategy was completed in June 2007, and therefore a more recent search into this area was warranted. French and colleagues ${ }^{25}$ found that no firm conclusions could be drawn with respect to the most effective type of intervention. However, they grouped studies by study design rather than by intervention type, and the statistically significant results associated with clinical decision support and reminder interventions were not detected. The authors also concluded that distribution of education materials did not seem to be an effective strategy to reduce imaging for low-back pain.

\section{Limitations}

The main limitation of our review is the number and quality of included studies. Only 7 studies met our inclusion criteria, and study homogeneity was insufficient to allow meta-analysis. Lack of sufficient power within the included studies resulted in lack of statistical significance despite apparent effect sizes of clinical importance. Four of the studies ${ }^{7,17,18,20}$ showed reductions in imaging between $10 \%-20 \%$ but did not show statistical significance owing to wide $95 \%$ CIs. We included only English-language literature; however, screening of English abstracts of the nonEnglish articles retrieved through the literature search showed that no relevant studies were excluded in the selection process because of this criterion. Only one of us performed the initial screening of article titles; however, only titles that were clearly irrelevant to the topic were excluded. Hence, this limitation is unlikely to have an impact on the conclusions of our review.

The predetermined inclusion criteria were selected to increase the validity of findings. We excluded a cluster RCT performed in 1993 that assessed guideline distribution ${ }^{32}$ because it reported imaging rates without distinguishing between imaging of the low back and imaging of the spine. The authors found a statistically significant decrease in referrals for imaging of the spine (risk ratio $0.7,95 \%$ CI 0.5 to 0.95 ); however, they did not account for clustering in the initial analysis, which decreased the validity of the result. We excluded 2 controlled before-after studies ${ }^{33,15}$ because of study design. One study assessed clinical decision sup- port in a hospital outpatient clinic and found a statistically significant decrease in imaging in the intervention group. ${ }^{33}$ The other assessed guideline distribution with audit and feedback and found no statistically significant results. ${ }^{15}$ These results are consistent with those found in our review.

\section{Conclusion}

Clinical decision support involving a modified referral form in a hospital setting and targeted reminders to primary care doctors of appropriate indications for imaging were interventions that significantly decreased the use of imaging for low-back pain by $36.8 \%$ and $22.5 \%$, respectively. These strategies are potentially low-cost interventions that would substantially decrease medical expenditures associated with the management of low-back pain.

\section{References}

1. Koes BW, Van Tulder M, Lin CC, et al. An updated overview of clinical guidelines for the management of non-specific low back pain in primary care. Eur Spine J 2010;19:2075-94.

2. Dagenais S, Tricco A, Haldeman S. Synthesis of recommendations for the assessment and management of low back pain from recent clinical practice guidelines. Spine J 2010;10:514-29.

3. Chou R, Qaseem A, Snow V, et al. Diagnosis and treatment of low back pain: a joint clinical practice guideline from the American College of Physicians and the American Pain Society. Ann Intern Med 2007; 147:478-91.

4. Williams CM, Maher C, Hancock M, et al. Low back pain and best practice care. Arch Intern Med 2010;170:271-7.

5. Dagenais S, Galloway E, Roffey D. A systematic review of diagnostic imaging use for low back pain in the United States. Spine J 2014;14:1036-48.

6. Mafi JN, McCarthy EP, Davis RB, et al. Worsening trends in the management and treatment of back pain. JAMA Intern Med 2013; 173:1573-81.

7. Eccles M, Steen N, Grimshaw J, et al. Effect of audit and feedback, and reminder messages on primary-care radiology referrals: a randomised trial. Lancet 2001;357:1406-9.

8. Chou R, Qaseem A, Owens D, et al. Diagnostic imaging for low back pain: advice for high-value health care from the American College of Physicians. Ann Intern Med 2011;154:181-9.

9. van Tulder MW, Assendelft W, Koes B, et al. Spinal radiographic findings and nonspecific low back pain: a systematic review of observational studies. Spine 1997;22:427-34.

10. Ash LM, Modic M, Obuchowski N, et al. Effects of diagnostic information, per se, on patient outcomes in acute radiculopathy and low back pain. AJNR Am J Neuroradiol 2008;29:1098-103.

11. Modic MT, Obuchowski N, Ross J, et al. Acute low back pain: MR imaging findings and their prognostic role and effect on outcome. Radiology 2005;237:597-604

12. Chou R, Fu R, Carrino J, et al. Imaging strategies for low-back pain: systematic review and meta-analysis. Lancet 2009;373:463-72.

13. Dagenais S, Caro J, Haldeman S. A systematic review of low back pain cost of illness studies in the United States and internationally. Spine J 2008;8:8-20.

14. Martin BI, Deyo R, Mirza S, et al. Expenditures and health status among adults with back and neck problems. JAMA 2008;299: 656-64.

15. Freeborn DK, Shye D, Mullooly J, et al. Primary care physicians' use of lumbar spine imaging tests. Effects of guidelines and practice pattern feedback. J Gen Intern Med 1997;12:619-25.

16. Suarez-Almazor ME, Belseck E, Russell A, et al. Use of lumbar radiographs for the early diagnosis of low back pain. Proposed guidelines would increase utilization. JAMA 1997;277:1782-6.

17. Matowe L, Ramsay C, Grimshaw J, et al. Effects of mailed dissemination of the Royal College of Radiologists' guidelines on general practitioner referrals for radiography: a time series analysis. Clin Radiol 2002;57:575-8.

18. French SD, McKenzie J, O'Connor D, et al. Evaluation of a theory-informed implementation intervention for the management of acute low back pain in general medical practice: the IMPLEMENT cluster randomised trial. PLOS ONE 2013;8:e65471. 
19. Dey P, Simpson C, Collins S, et al. Implementation of RCGP guidelines for acute low back pain: a cluster randomised controlled trial. Br J Gen Pract 2004;54:33-7.

20. Schectman JM, Schroth S, Verme D, et al. Randomized controlled trial of education and feedback for implementation of guidelines for acute low back pain. J Gen Intern Med 2003;18:773-80.

21. Kerry S, Oakeshott P, Dundas D, et al. Influence of postal distribution of the Royal College of Radiologists' guidelines together with feedback on radiological referral rates on x-ray referrals from general practice: a randomised controlled trial. Fam Pract 2000; 17:46-52.

22. Carton M, Auvert B, Guerini H, et al. Assessment of radiologica referral practice and effect of computer-based guidelines on radiological requests in two emergency departments. Clin Radiol 2002;57:123-8

23. Blackmore CC, Mecklenburg R, Kaplan G, et al. Effectiveness of clinical decision support in controlling inappropriate imaging. J Am Coll Radiol 2011;8:19-25.

24. Baker SR, Rabin A, Lantos G, et al. The effect of restricting the indications for lumbosacral spine radiography in patients with acute back symptoms. AJR Am J Roentgenol 1987;149:535-8.

25. French $\mathrm{S}$, Green $\mathrm{S}$, Buchbinder R, et al. Interventions for improving the appropriate use of imaging in people with musculoskeletal conditions. Cochrane Database Syst Rev 2010;(1):CD006094.

26. Cochrane Effective Practice and Organisation of Care Group (EPOC). Data collection checklist. Ottawa: The Centre for Practice Changing Research; 2002. Available: http://epoc.cochrane.org /sites/epoc.cochrane.org/files/uploads/datacollectionchecklist.pdf (accessed 2015 Feb. 9).

27. Moher D, Liberati A, Tetzlaff J, et al.; PRISMA Group. Preferred reporting items for systematic reviews and meta-analyses: the PRISMA statement. PLoS Med 6(7):e1000097. Available: http://journals.plos.org/plosmedicine/article?id=10.1371/journal .pmed.1000097 (accessed 2015 Feb. 9).

28. EPOC-specific resources for review authors. Oslo: Norwegian Knowledge Centre for the Health Services; 2014. Available: http:/ epocoslo.cochrane.org/epoc-specific-resources-review-authors (accessed 2015 Feb. 9)

29. Higgins JPT, Green S, editors. Cochrane handbook for system- atic reviews of interventions. Version 5.1.0. Oxford: Cochrane Collaboration; 2011. Available: www.handbook.cochrane.org (accessed 2015 Feb. 9).

30. Grimshaw JM, Thomas R, Maclennan G, et al. Effectiveness and efficiency of guideline dissemination and implementation strategies. Health Technol Assess 2004;8.e1.

31. Ramsay C, Matowe L, Grilli R, et al. Interrupted time series designs in health technology assessment: lessons from two systematic reviews of behavior change strategies. Int $J$ Technol Assess Health Care 2003;19:613-23.

32. Oakeshott P, Kerry S, Williams J. Randomized controlled trial of the effect of the Royal College of Radiologists' guidelines on general practitioners' referrals for radiographic examination. $\mathrm{Br}$ J Gen Pract 1994;44:197-200.

33. Ip I, Gershanik E, Schneider L, et al. Impact of IT-enabled intervention on MRI use for back pain. Am J Med 2014;127:512-8.

Affiliations: Department of Health Professions (Jenkins, Hancock), Macquarie University, Sydney, Australia; School of Rehabilitation Therapy (French), Queen's University, Kingston, Ont.; The George Institute for Global Health (Maher), Sydney Medical School, The University of Sydney, Sydney, Australia; Department of Chiropractic (Engel), Macquarie University, Sydney, Australia; Australian School of Advanced Medicine (Magnussen), Macquarie University, Sydney, Australia

Contributors: Hazel Jenkins, Mark Hancock and Simon French contributed to the study concept and design. All of the authors were responsible for the collection, analysis and interpretation of data. Hazel Jenkins and Mark Hancock drafted the manuscript, and all of the authors critically revised it for important intellectual content. All of the authors approved the final version submitted for publication and agreed to act as guarantors.

Funding: No funding was received for this study.

\section{A credit to you!}

CMA members can earn CME credits for reading $C M A J$ articles

The CMAJ is committed to helping meet your accredited learning goals. CMA members can earn CME credits simply by reading the CMAJ. Selected CMAJ articles are eligible for Mainpro-M1 credits from The College of Family Physicians of Canada (CFPC). Members can also obtain Mainpro-M2 credits or MOC (Section 2) credits from Royal College of Physicians and Surgeons of Canada (RCPSC) for reading any article in CMAJ.

\section{Learn more}

www.cmaj.ca/site/cme

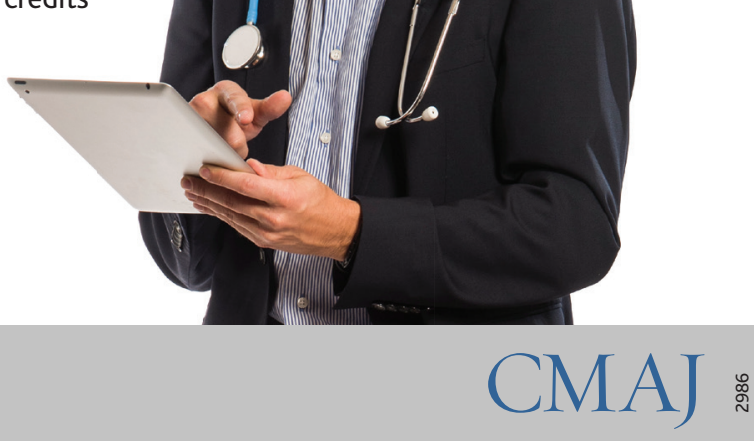

